\title{
Gredo de libertad. La primera poética de Miguel Fernández
}

\author{
SULTANA WAHNON \\ Universidad de Granada
}

\section{A MANERA DE JUSTIFICAGIÓN}

La obra de un poeta nunca se presenta de una vez. El lector que relee la obra, años después de haberla leído por primera vez, no es nunca el mismo de antes. Cada nuevo encuentro con una obra tiene sus propias circunstancias, un trasfondo diferenciado de resonancias y de estímulos. Mi propuesta en este artículo, que quiere ser homenaje a la memoria de quien fue admirado poeta y buen amigo, es una relectura, inevitablemente parcial y selectiva, de la poética que subyace a su primer libro, Credo de libertad. Mi hipótesis es que una gran parte de los poemas de este libro ilustra sobre una poética de la memoria de la que es piedra angular la meditación sobre el tiempo y la redención del pasado olvidado. Aunque por razones de espacio voy a centrarme sobre todo en el análisis de los poemas de Credo de libertad, las conclusiones podrían extenderse a buena parte del resto de su obra y especialmente a muchos de los poemas de Sagrada materia y Juicio final.

DISOLUCIÓN DE LA METAFÍSICA EN CREDO DE LIBERTAD

Cuando en la década de los cincuenta poetas como Gabriel Celaya o como Pablo Neruda ordenaban su canto a la esperanza de construir un 
futuro mejor para el mundo, la de Miguel Fernández era una voz disonante en el armónico concierto de las voces de la poesía social, y no porque su poesía careciese de "mensaje", sino porque el que transmitía era muy diferente del de la poesía social. La peculiaridad del mensaje de Miguel Fernández en Credo de libertad no consiste, sin embargo, como la mayor parte de la crítica creyó, en su religiosidad. En opinión de Gadamer (1977: 72). es preferible evitar la palabra "religión" donde no hay una comunidad religiosa que le dé un sentido concreto. La palabra de Miguel Fernánde\%, tan solitaria como la de Rilke, no puede ser calificada de "religiosa" en sentido estricto, por mucho que el pocta pueble su obra de motivos y símbolos religiosos. Por el contrario, se inscribe, ya desde los primeros tres libros, en el interior del inmenso vacío que habría dejado la ausencia de Dios (1), y la profunda gravedad de muchos de sus poemas se deriva precisamente del abandono radical del vínculo con las religiones y con el mundo de la fe. Los de Credo de libertad (1958) están impregnados de la convicción de que Dios está lejano, y ninguna evocación de creencias cristianas, judías o humanistas pueden ocultarnos esa lejanía. No importa que el primer poema del libro se titule "Resurrección" ni que los últimos se llamen Dos "Salmos de aceptación", como tampoco importa que otro de los poemas del libro se titule "Carta a un cura rural". Estamos ante una poesía de la lejanía de Dios que nombra a Dios en primer y principal lugar para rellenar su ausencia, aunque también — como veremos - lo hace para rellenar otra ausencia todavía más innombrable que la de Dios y que es la que sitúa la poesía de Miguel Fernández en una contemporaneidad más cercana a nosotros que la de otros poetas dejados de la mano de Dios como Rilke.

Pues, por la misma razón de ser una poesía nacida de la nostalgia de Dios sin ser ajena a una honda, auténtica preocupación social, la respuesta que se da en ella a la cuestión de una humanidad más justa —cuestión básica de la llamada "poesía social" - es muy diferente a la que predominaba en la poesía de los años cincuenta en España. El poema ya citado que lleva el título de "Resurrección" y en el que me voy a centrar en primer lugar, nos da las claves para adentrarnos en el mensaje que la voz de Viguel Fernández trató de hacer llegar a una sociedad que, recién salida 
de una guerra nacional y otra mundial, y una vez más en la historia de Occidente, se dejaba fascinar por los cantos de sirena del futuro.

Como ya he señalado, el de Dios no es el único vacío que puebla la poesía de Miguel Fernández. Más importante aún que éste, si cabe, es el de la idea de progreso, pilar y fundamento de la racionalidad occidental y del humanismo. En "Resurrección" (P. C.: 44-45) (2), se hacen patentes las dos ausencias, pero especialmente la última. El poema se confiesa incapaz de anunciar a las generaciones futuras, a "esa descendencia que se vierte/ gozosa por los parques", un tiempo nuevo al que deban ordenar su esperanza y, por lo mismo, se abre con una interrogación acerca de cuál podría ser el contenido de ese mundo nuevo:

"¿Cuál es tul anunciación?

Acaso un son, trompetas amarillas

por la aurora; un planeta entreabierto

llenándonos de estrellas los países".

Así, entre solemne e irónico, Miguel Fernández renuncia a rellenar los sueños de futuro de la estirpe humana con fantasías tales como un son, trompetas amarillas o países llenos de estrellas. Podría rellenarlos con realidades aparentemente más conocidas como "paz" o "libertad", pero también se duda de que la esperanza de la estirpe humana en un mundo mejor para que el futuro pueda cifrarse en dos palabras que, por decirlo en términos derrideanos, difieren siempre su referente:

\footnotetext{
"Se espera

que tú vengas. Decíamos, 'La paz...'

y a esta invocación, igual que una pared

que se alarga, te ibas alejando.

'La libertad quizás' (...)"
}

Lo que queda, tras la revisión de todos los ideales con que se ha rellenado en la historia de Occidente la imagen del futuro, es el vacío de una estructu- 
ra en la que falta - también como en la estructura derrideana- el centro:
"Decíamos, "Entre la paz y tú
cogemos lo de en medio'. (Nos llenamos
las manos de vacío, el único habitante
que quedaba en el centro)".

No se oculta en el poema que el deseo de centro, el sueño de la especie humana es tan inagotable que acaso tenga ya "otro nombre / sobre cada conciencia", pero ese deseo, hecho nombre en la conciencia, es una vieja costumbre, un hábito de la historia, que quizás ha servido no tanto para mejorar la historia como para convertirla en un gigantesco almacén de desechos:

\footnotetext{
"Pero igual que la red que llega al fondo

y su peso es un cofre, una leyenda

olvidada en el mar, que ahora resurge

en la boca de un pez plateado

y se vuelve a arrojar como un desecho

porque no vive el hombre de la historia

sino en la realidad de la barca gastada,

acaso te perdamos cada hora

de estarte adivinando...".
}

Auténticas realidades defectivas - realidades sin más realidad que la que les da el hecho de ser nombradas-, la paz y la libertad "de aquel mundo" siempre desconocido, que "acaso nunca exista, en mis hijos / tal vez", son, por tanto, otras ausencias que, como la de Dios, son nombradas sólo en razón del hábito de la nostalgia. Con la conciencia de su carácter de hábito $\mathrm{y}$, por tanto, con la pérdida de la mirada simplificadora del mismo, Miguel Fernández coloca su poesía fuera de la antigua casa del lenguaje, inscribiéndola en ese momento histórico de la filosofía que se conoce como posmetafísico o como nihilista. 
El poema titulado "Aquel tiempo" (P. C.: 46-47) ilustra sobre la conciencia con que Miguel Fernández se sitúa fuera de la vieja casa del lenguaje. Lo que se representa en este poema es "aquel tiempo" en el que el lenguaje tenía sentido y estaba constituido de palabras plenas, de presencias no diferidas. Este tiempo se presenta como tiempo perdido, como pasado irrecuperable.

El tiempo en el que Dios estaba presente y "los panes, / rubios como una túnica / esperaban tu bendición" es imposible de recuperar, como lo demuestra el hecho de que incluso la memoria tenga dificultades para situarlo en un momento preciso: "No recuerdo qué tiempo / fue aquel...". La dificultad de recuperar ese mundo se hace perceptible mediante el recurso de mostrar los problemas de la memoria para restablecerlo en su totalidad y mediante la expresión de una duda a cerca de su realidad tangible:

"Quizá me mienta la memoria.

tal vez lo haya soñado

aunque en las manos tenga

sus cortezas más duras, las hojas quebradas

de la harina, el sabor

de la casa en el alma.".

Cuando, venciendo las dificultades, se nombran las características de ese tiempo soñado, lo importante es comprobar que en el mundo ordenado por la presencia de un garante sobrenatural, las palabras "paz" y "libertad" tenían un significado pleno:

"descubrimos que el corazón es libre

en la paz, que el amor nos hacía

radiantes, sencillos como el agua,

y la libertad era ese amor

entre cada vaso de ternura, puesto allí, destilando piedad sobre la casa". 
Pero es igualmente importante comprobar que el regreso a la casa del lenguaje se siente imposible y que el poema —al ser incapaz de situar el momento concreto en que el sueño se ha realizado- hace de ese lenguaje pleno y ordenado, constituido de presencias, el lugar de una ausencia a la que se dirige la nostalgia del poeta, trasunto de la aspiración utópica de toda la humanidad:

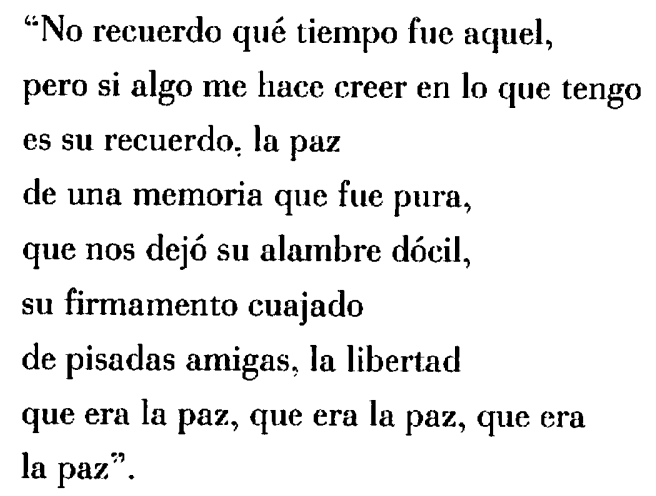

Pero este poema, que pone en escena la pérdida del lenguaje, nos sitúa también frente a la actitud elegida por Miguel Fernández para sobreponerse a ella. Puesta frente a un tiempo en el que ya no es posible hablar, la poesía de Miguel Fernández vence la tentación del silencio, la fascinación aurática de la nada, la atracción del abismo y trata de ir más allá de los escombros —o desechos- de la razón clásica, más allá del luto por el derrumbe del lenguaje, mediante el recurso a la memoria del pasado (cfr. Rella, 1981:15). Credo de libertad explora el vacío, la vacua libertad que llega de la retractación de lo divino y de lo humano divinizado. Y es el vacío, la ausencia de sentido la que obliga a esta poesía a dejar de mirar hacia adelante para volver lo ojos al pasado "como si fuera / posible comprenderte, ir descubriendo huellas / allá donde los vivos no han oído tu nombre". De ahí el valor excepcional en el poema "Resurrección" —al que volvemos- de esos cuatro versos que, separados del resto del poema, invocan no a los niños del futuro sino a los del pasado, a los que están - por decirlo en palabras de Rilke- "infinitamente muertos": 
"Invoco aquel país, a sus columnas

tan blancas como el miedo,

a los niños caídos en las calles

con un carbón sobre la dentadura".

Es inútil tratar de identificar a este país y a estos niños, buscarles el referente concreto de la España de la guerra civil: "aquel país" —el del pasado muerto- cumple en el poema la función de oponerse significativa y estructuralmente a "aquel mundo" el del futuro soñado. $\mathrm{Y}$, por tanto, expresan la voluntad de escuchar los mensajes que provienen de las épocas que han precedido al poeta antes que la de tratar de "adivinar" los mensajes que llegan de un futuro que, como se vio, se perdía a cada hora de estarlo adivinando. En este sentido, es lo que Vattimo (1991:11) llama la pietas, es decir, la atención devota a todas las huellas de vida en la historia de la humanidad, la actitud predominante en Credo de libertad. La rememoración piadosa de Heidegger, la "fiesta de la memoria" de Nietzsche, encuentran un correlato poético en este deambular por la historia que caracteriza la primera producción de Miguel Fernández.

FIGURAS DE LA DIFERENCIA: EL JLDÍO EN CREDO DE LIBERTAD.

Aún nos queda por analizar la consecuencia más importante del poema "Resurrección", aquella que puede precisamente explicar su título. El uso de un término procedente del lenguaje cristiano no implica, como ya se vio, religiosidad en sentido estricto, pero sí implica que la religiosidad no ocupa ya el lugar de la "fábula" o la "mentira" frente a las grandes verdades de la razón. La crisis de la idea de progreso, al poner al mismo nivel de realidades defectivas —es decir, al nivel de construcciones de lenguajevalores humanistas y valores religiosos, permite un uso equiparable de ambos: la rememoración piadosa no va a tener como único objeto los grandes valores perdidos de Occidente, sino también la religiosidad tradicional. En palabras de Vattimo (1991: 32): 
Sultana Wahnón

"una vez que descubrimos que todos los sistemas de valores no son sino producciones humanas, demasiado humanas, ¿qué nos queda por hacer? ¿Liquidarlos como a mentiras y errores?. No, es entonces cuando nos resultan todavía más queridos, porque son todo lo que tenemos en el mundo, la única densidad, espesor y riqueza de nuestra experiencia, el único "ser" $"$

Esto mismo explica que Miguel Fernández rescate los mensajes de los otros, las culturas de los grupos que la modernidad habría despreciado. El fracaso asumido del proyecto moderno le permite escuchar las voces de los que, desde la perspectiva de la temporalidad se quedaron en el pasado. Un resto del pasado es, sin dudar el judío. Habituado, sin embargo, por su convivencia con judíos reales en Melilla - una experiencia que pocos poetas españoles han podido compartir-, a considerarlos parte del presente, en una concepción anticipadora de la simultaneidad del tiempo histórico, el poema "Las tumbas de los judíos" ( $P$. C.: 53-54) da voz a la "diferencia" y sanciona por eso la fisura de la homogénea racionalidad occidental. Aquello que carecía de sentido y, por tanto, de valor en la escena de la racionalidad clásica se presenta como experiencia histórica, como forma simbólica y como trazo de vida que pide y debe ser escuchado con pietas, tanto más por cuanto esa experiencia judía del mundo es, precisamente, la de la memoria:

"Las tumbas de los judíos son planas como una memoria, sepultan su recuerdo dentro de un ánfora de inquietudes y lloran entre copas de alcohol cubriéndose los cinco sentidos".

Los judíos representan, en Credo de libertad, la resistencia a esa manera occidental y racionalista de vivir el tiempo y la historia mirando siempre hacia adelante, hacia el futuro, hacia el ideal de los descendientes libres y felices. Con los ojos puestos en el pasado y en la muerte, la "costumbre" de llorar el pasado de los judíos es una alternativa al "hábito", ya cuestionado, de adivinar el futuro que caracteriza a las ideologías del progreso: 
"mientras el rito los sacrifica con el tedio de las costumbres, prosiguen su llanto por los días interminables de la muerte.

Los judíos se apoyan para llorar en las paredes eternas del tiempo".

Sólo una lectura demasiado apegada a los valores de la modernidad connotaría negativamente los términos "rito", "tedio", "llanto", "muerte", que se ponen en juego en estos versos. Desde la perspectiva de la pietas nihilista, en cambio, todos ellos simbolizan la detención del tiempo que se hace necesaria tras el fracaso del proyecto moderno. La atención devota hacia los trazos del pasado precisa de una voluntad de sacrificar la propia vida futura lo que ésta podría llegar a ser utópicamente. La poesía de Miguel Fernández pone en práctica una voluntad decidida de mirar hacia el pasado y de llorar interminablemente a los muertos, pues éstos son la única evidencia, la única verdad que se le aparece al hombre que habita en el vacío:

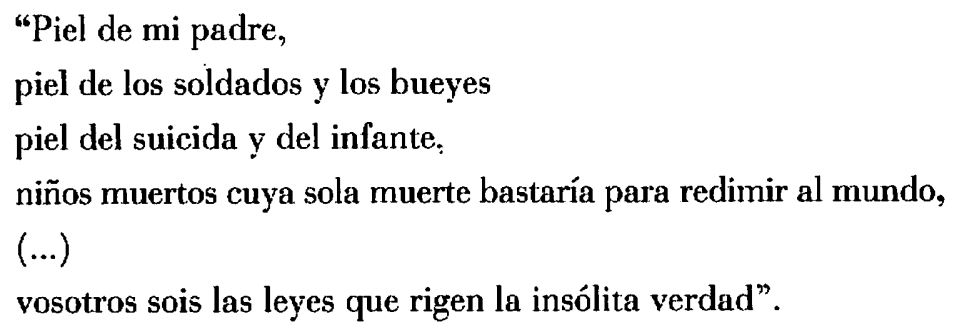

La primera poética de Miguel Fernández se apoya, pues, en la apariencia judía del tiempo que Walter Benjamin describió en sus Tesis de filosofía de la historia:

"Se sabe que a los judíos les estaba prohibido investigar el futuro. En cambio, la Torah y la plegaria los instruían en cuanto a la memoria. Esto los liberaba de la fascinación del futuro, a la que sucumben aquellos que buscan información en los adivinos" (Benjamin, 1940: 89).

En La razón de los vencidos el filósofo español Reyes Mate ha desarrollado estas intuiciones de Benjamin contraponiendo la dialéctica de la Ilus- 
tración al espíritu judío (v. Mate, 1991). Sin tratar de establecer identificaciones innecesarias -además de peligrosas- entre espíritu judío y judíos ni entre espíritu ilustrado y europeos; sino al contrario, es decir, tratando de demostrar en qué medida el espíritu judío ha estado presente siempre en la cultura occidental incluso cuando se lo ha negado, la reflexión de Reyes Mate nos permite entender la atención que Miguel Fernández prestó no sólo a los judíos, sino también a la esperanza cristiana de la resurrección, como un claro indicio de que sus primeros libros ya habría hecho agua la dialéctica ilustrada y de que, por consiguiente, en ellos se prefiere el recuerdo a la razón (Mate, 1991: 185).

\section{LA REDENCIÓN DEL PASADO}

Se entiende mejor ahora que ese rostro que en "Resurrección" me volvía para mirar a "los niños caídos en las calles / con un carbón sobre la dentadura" ( $P . C .: 45)$ es idéntico al rostro que en "Las tumbas de los judíos" se vuelve hacia la pared donde llora por "los días interminables de la muerte" ( $P$. C.: 53). La experiencia que la poesía de Miguel Fernández nos transmite es, por tanto, ésa que Walter Benjamin atribuía al Ángelus Novus, al Ángel de la Historia: la del ángel que tiene las alas tendidas y podría echar a volar hacia el futuro, pero se niega a hacerlo porque tiene la mirada clavada en el catastrófico pasado y quisiera volver atrás para despertar a los muertos y recomponer lo despedazado (Benjamín, 1940: 82). Una imagen precisamente muy similar a la del ángel benjaminiano - trasunto a su vez del judío Jesús - la encontramos en "Las Bienaventuranzas", el poema final de Sagrada materia (1967), donde "los pobres del secano", "los mansos", "los pacíficos", "los que fueron calcinados en Auschwitz" reciben la solemne promesa de un "hombre tan sólo" que, "clavado en el paisaje con sus manos tendidas, / siempre os redimirá con su amor por delante" (P. C.: 102-3).

Tenemos que detenernos en esta promesa de redención de los muertos. Los niños caídos en las calles, los que fueron calcinados en Auschwitz, todos los que, en fin, están infinitamente muertos reciben la promesa de la redención por el amor. De nuevo nos encontramos ante un razonamien- 
to que remite no a la razón occidental - que promete un paraíso en la lierra a los que todavía no han nacido-, sino a la tradición judeocristiana, que "bebe de una promesa de felicidad eterna hecha al hombre en la noche de los tiempos" (Mate. 1991: 224). Cuando el sueño no ha llegado a tiempo y los hombres que soñaron se han marchado para siempre. puede que -como se dice en un poema de Sagrada materia - sólo sea la última esperanza, / desear que golpeen la puerta de la resurrección" (P. C.: 82). Pero cuando Miguel Fernández recuerda esta promesa, lo hace sobre un escenario del que Dios está ausente - "Dios está muy lejos para una respuesta". ("Elegía para un suicida". P. C.: 61) - y en el que, por tanto, el hombre está definitiva, radicalmente solo. Así lo confirma, a pesar de su título, el "Salmo del nuevo año", el poema que cierra Credo de libertad (P. C.: 68-69):

\section{"Estamos siempre solos}

bajo estas guerras suspendidas por el norte y el este.

por el sur y el cautiverio.

por el oeste de afiladas montañas

y a Ti llegamos, como

esos ciervos perdidos en un bosque inconcreto

sirn poder gritar, porque las lianas

se enredan a la voz del que pide el camino".

Si Dios está ausente, las esperanzas conservadas en las tradiciones religiosas no pueden ser satisfechas, a menos que, como se decía en "Las Bienaventuranzas", un "hombre tan sólo" se erija en redentor de la defraudada y estafada especie humana. Hace falta, en cfecto, que alguien asuma la labor que el Dios ausente no puede ya asumir: en el escenario posmetafísico la resurrección de los muertos es una responsabilidad exclusivamente humana. Ese redentor humano que toma a su cargo la labor divina de hacer justicia a los muertos que sufrieron es el hombre de las manos tendidas que se dibujaba en "I as Bienaventuranzas". Pero la única manera que el hombre tiene de resucitar a los muertos y hacerles justicia es la memo- 
Sultana wahnón

ria, la experiencia judía del tiempo y la historia como llanto interminable por los muertos. La memoria del pasado olvidado es poética que surge, pues, del afán de superar el aspecto de injusticia de la vida humana en su dimensión exclusivamente temporal. La misión del poeta nihilista es preservar todo lo que desaparece, sin estar no obstante muy seguro da que sus esfuerzos puedan salvar a las personas, las cosas y las ideas de caer irremediablemente en el olvido.

No tiene, por tanto, nada de extraño que Miguel Fernández conciba su poesía como memoria y redención del pasado. Esta primera poética de Miguel Fernández, que iría transformándose —en proceso que no voy a estudiar aquí- a partir de Monodia (1974), se hace explícita muchas veces en los poemas de sus primeros libros, ya en Credo de libertad, donde puede leerse:

"Recuerda, aún es tiempo de recordar los días

que pesaban como enormes templos;

recuerda tu manta de colores para ocultar los desgarros,

las calles con la humedad de su tedio

la familia y las tabernas y las tradiciones que

cercaron tu sonrisa para siempre"

(Elegía para un suicida, P. C.: 61).

Pero sobre todo a partir de Sagrada materia (1967):

"Como el salterio, abre tu libro, amigo mío,

y ponte a pensar en la humilde historia que te cubre" (P. C.: 73).

"Porque tan sólo muere

aquello que ya nunca nos crece en la memoria" (P. C.: 87).

UNA HISTORIA DE REPETICIONES

Lo que el rostro del ángel de la historia ve, cuando vuelve la cabeza para mirar atrás, es el pasado en su totalidad de dolor y esperanzas frustradas. En los primeros libros de Miguel Fernández es, por tanto, percepti- 
ble la decisión de atender a la parte más dolorosa y humilde del pasado. EI pasado que interesa a Miguel Fernández no es el pasado de los vencedores, que se ha conservado en los libros de historia (Mate, 1991: 224), sino el pasado de los vencidos, el de aquellos humildes, mansos, pacíficos, pobres de secano, que no han pasado a los libros de historia, aunque fue de su sacrificio del que se nutrió la victoria de los héroes. En "Los mendigos", otro poema de Credo de libertad (P. C.: 52-53), Miguel Fernández sitúa el origen de esta humilde historia nada menos que "cinco mil años antes de la era de Cristo". En el mismo poema los mendigos que vivieron cinco mil años antes de la era de Cristo "llaman cada mañana desde el fondo del tiempo" a "este Miguel" para que él les preste su voz, "que los llama los puros, los cercanos, los elegidos". Si tiene que prestarles su voz es porque los mendigos carecieron de ella: su salmo no fue escrito, sino "grabado en piedra de sacrificios" (P. C. 53). Es coherente que en el primer poema de Juicio final (1969) se diga, por cierto en un alarde de polifonía bajtiniana que va a ir aumentando a lo largo de su producción posterior: "No serían verdad los días que me diste/ si no te hablara siempre en las voces de ellos" (P. C. 108).

Son muchas las cosas que Miguel Fernández aprende y nos enseña al mismo tiempo en esa memoria passionis, en ese recuerdo del sufrimiento pasado, que es su primera producción poética. Prestando su voz a los hombres del pasado, y entre ellos especialmente a los que carecieron de ella, nos transmite una vieja sabiduría que cobra expresión, por ejemplo, en el poema 7 de la primera parte de Sagrada materia (P. C.: 79-80). El poema comienza con una escena humilde y cotidiana: la del hombre que cada mañana viene a trabajar "con el recuerdo del café y la rebanada de manteca amarilla, /en el cielo de la boca". Esta escena trae consigo la evocación de otra escena similar que se sitúa en el pasado: la de "los antepasados del jornal", aquellos

"que los domingos hacían colada de sus ropas

y por la calle abajo,

donde el verdín de la humedad preparaba sus cauces se arrastraba el río sucio del sudor". 
El poema sigue retrocediendo en el pasado. Va "repasando" su "linaje de obreros", recordando a "Padres, abuelos, hombres" que "jamás (...) hablan desde su muda ceniza", y en este incesante ir hacia atrás acierta a dibujar la imagen de la historia como repetición: "Seguimos igual que los antepasados del jornal, / mi soleada estirpe heroica". El final del poema es, en consecuencia, un golpe bajo a la dialéctica de la Ilustración: "Esta es la humilde historia del trabajo / y sigue el tiempo y pasa / un relevo de manos, de oscuras cicatrices". La superstición progresista según la cual el mundo progresa imparablemente hacia lo mejor es sustituida aquí por la imagen, extraída de un breve recorrido por la verdadera experiencia histórica, de un mundo repetido, en una especie de eterno retorno que deja poco resquicio a la esperanza de un futuro diferente. El mundo parece aquí como en el poema "La llanura", "un planeta obsesivo / que no encuentra un buen sitio para parar su rueda" (P. C: 56).

Igual que se repite el trabajo, se repite el dolor. El poema 8 de la primera parte de Sagrada materia (P.C.: 80-81) describe una escena familiar que no tiene tiempo ni espacio definido porque podría ocurrir en cualquier momento y en cualquier lugar. Es la escena de una "congoja" que se desarrolla silenciosa "en cualquier casa". Los habitantes de la casa, unos padres ya ancianos, "tienen fijos los ojos en la esquina, / petrificados" y "las pupilas llovidas de amargura". Ahondando en la escena familiar, se nos describe al padre "la mejilla en la mano", sintiendo "el frío morir en sus dedos obreros" y apartando "con el bastón / la ceniza dispersa en las rojas baldosas". Por su parte, la madre, "sobre el vientre cruzadas / las manos", está mordiendo "la sal de una perdida lágrima". Ambos permanecen "absortos en el fuego del hogar, / en donde purifican felices recuerdos de otros días". Este dolor silencioso, congoja de los humildes, que nunca ha sido escrita, cobra voz en los versos en que se nos revela por fin la causa de tanto dolor: la "lentísima espera de que golpeen la puerta/ por donde ya salieron y de nuevo/ volverán a cruzar los hijos de regreso". Una historia humilde y repetida en la que, como en la del trabajo, solo cambian los protagonistas. Empeñada en sacar a flote los 
aspectos más olvidados de la historia, se diría que la poesía de Miguel Fernández nace de la convicción de que las cosas más recónditas, los interiores despreciados contienen "el secreto de lo radicalmente histórico del pasado" (Mate, 1991: 225).

\section{UNA APUESTA POR LA TRASCENDENCIA}

La memoria que redime el tiempo perdido hace nacer una extraña y extraordinaria felicidad. Pese al desarraigo de la antigua casa del lenguaje, pese a la falta de fundamentos con que se inicia la travesía poética. pese a la ruptura de la temporalidad lineal que impide la fe en un curso unitario de la historia y en un sentido de emancipación, Credo de libertad y los dos libros posteriores son un "salmo de aceptación", un enorme sí a la vida. Hay en la poesía de Miguel Fernández una apasionada confesión de la existencia terrenal, incluso en su extrema miseria, necesidad y contingencia. No hay en ella ninguna afirmación que nos engañe la vida "diciendo: "El porvenir será vuestro milagro" ("Salmo del nuevo año", (P. C.: 69). Pero si una afirmación de lo que de milagro tiene la vida incluso en su imperfección. Son muchos los poemas que en Credo de libertad insisten en la evidencia de la belleza de la naturaleza y la humanidad, evidencia que se impone sobre los más penosos recuerdos de la historia. "La cosecha" (P. C.: 48) es uno de ellos. En él, lejos de compadecerse por la caducidad de las cosas, en lugar de perderse en la contemplación de la nulidad de este mundo, se trata de hacer imperecedero lo que está - por naturalezacondenado a ser perecedero: la "materia sagrada del olivo". En el poema el olivo no es sólo el árbol, el objeto real condenado a la caducidad: es también el olivo recreado por la mano del hombre, metáfora del poeta. Sustituyendo de nuevo al Dios ausente, y al mismo tiempo que se esfuerza en redimir lo ya desaparecido, el poeta concede eternidad a lo que, todavía vivo, está irremediablemente destinado a morir. "Niño celeste" ( $P$. C.: 48-49) es el-poema que sigue a "La cosecha" y que elabora la imagen del poeta - ser celeste - como "salvador del orbe" que tiene potestad sobre la muerte: 


\begin{abstract}
"Algo subsiste para que tú mueras, niño celeste, salvador del orbe, crecido como un árbol que alimenta su potestad sobre la muerte ajena".
\end{abstract}

"Historia de un insecto" ( $P$. C.: 49-50) es también relato de una vida -en este caso animal - que, condenada a la caducidad por la ley natural - "el insecto cumple su pequeño destino secreto"-, alcanza existencia eterna en el poema, en las páginas de un libro que salva su belleza de la muerte definitiva:

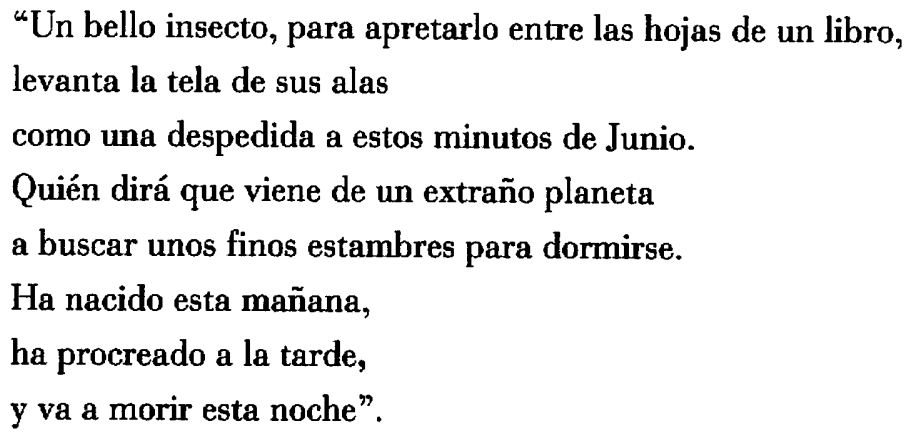

La misión del artista consiste en preservar "entre las hojas de un libro" todo lo que desaparece, transformando la piedra, el color, el sonido en palabras. Lo que se escucha, en medio de todos los cambios, en el seno de la caducidad, es la permanencia de la naturaleza y de la voz humana como parte de ella. Si en el recorrido por la historia se recordaban los interiores más humildes y despreciados, en el recorrido por la naturaleza son también las cosas más pequeñas - el olivo, el insecto, la gota de agua- las que reciben la amorosa atención del poeta. En el "Salmo de la gota de agua" (P. C.: 67-68) esta voluntad se hace explícita:

"Te busco en las cosas pequeñas para verte, ahí arriba, donde la presencia diminuta de la dicha, balancea el milagro, la leve eternidad de una gota de aguan. 
Son tiempos de crisis y de precariedad reconocidas, pero la poesía de Miguel Fernández no cede a la tentación mefistofélica de la nada, a "la dimensión trágica y demoníaca de la voluntad que se precipita en la nada porque a nada quiere renunciar" (Rella, 1981: 89). Después de abandonar la creencia en Dios, la poesía es la esencia que ocupa su lugar como redención de la vida y como dadora de sentido: rastreando en las cosas pequeñas la "presencia real" que garantice la eternidad del significado. En este sentido la obra de Miguel Fernández se constituye en ejemplo privilegiado de lo que George Steiner ha llamado "una apuesta en favor de la trascendencia" (Steiner, 1989: 14). Cuando una voz humana se dirige a otra para encomendarle la sagrada tarea de redimir el pasado olvidado, está apostando muy fuerte por el significado del significado. Si el poema se configura como única posibilidad de redimir la vida, es porque se cree capaz de encontrar al otro, al lector, que en su condición de libertad ha sido esperado para dar cumplimiento a la promesa de la vida eterna en el poema. 
1. Puede verse a este respecto mi libro El irracionalismo en la poesin de Miguel Fernindez, Granada, Antonio Ubago Editor, 1983, p. 67.

2. Cito por Miguel Fernández, Poesía completa (1955-1980), Madrid, Espasa Calpe, 1983. Las páginas irán entre parćntesis en el texto.
BENJAMIN, Walter (1940), Tesis de filosofia de la historin, en Angelus Nonus, Barcelona Editorial Sur, 1970, pp. 77-89.

FERNÁNDEZ, Miguel (1958), Credo de libertad, Tetuán. Mirto y Laurel.

(1967), Sagrada materia, Madrid, Rialp (1969), Juicio final, Madrid,

Biblioteca Nueva.

GADAMlER. Hans-Georg (1990),

"Rainer María Rilke, cincuenta años después", en Poema y diálogo. Ensayos sobre los poetas alemanes más significativos del siglo XX. Barcelona, Gedisa, 1993, pp. 62-79.

MATE, Reyes (1991), La maón de los vencidos, Barcelona, Anthropos.

RELLA, Franco (1981), El silencio y las palabras. El persamiento en tiempo de crisis. Barcelona, Paidós, 1992.

STEINER, George (1989), Presencias reales, Barcelona, Destino, 1991.

VATTIMO, Gianni (1991), Ética de la imerpretación, Barcclona, Paidós. 


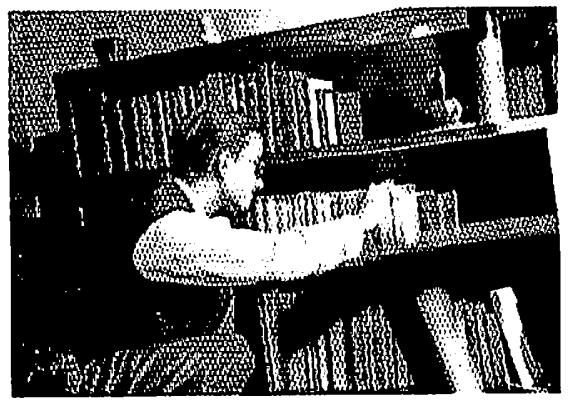

Miguel Fernández en la

- biblicteca de su cosa, 1948.

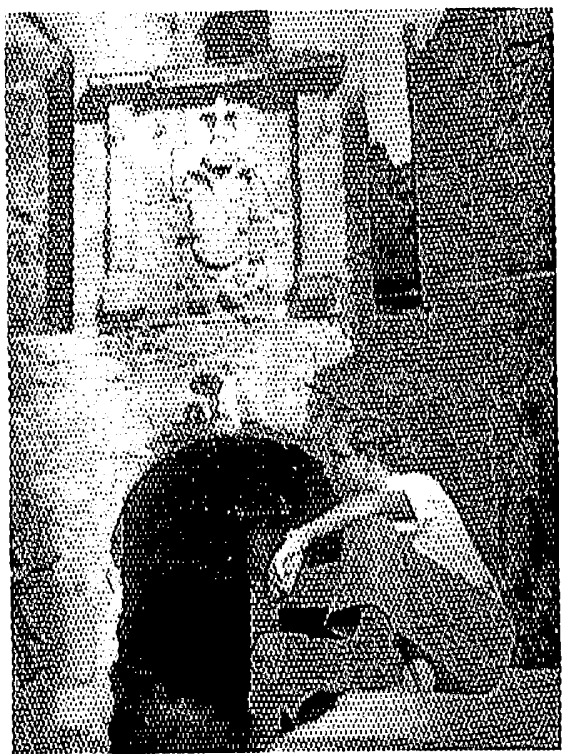

Miguel Fernóndez en la Puerta de Santiago, Melilla la Vieja, 1948.

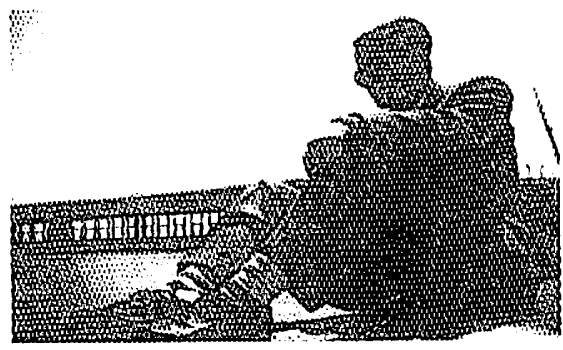

Miguel fernández desde Melillo la Vieja, con el cargadero del mineral al fondo. 


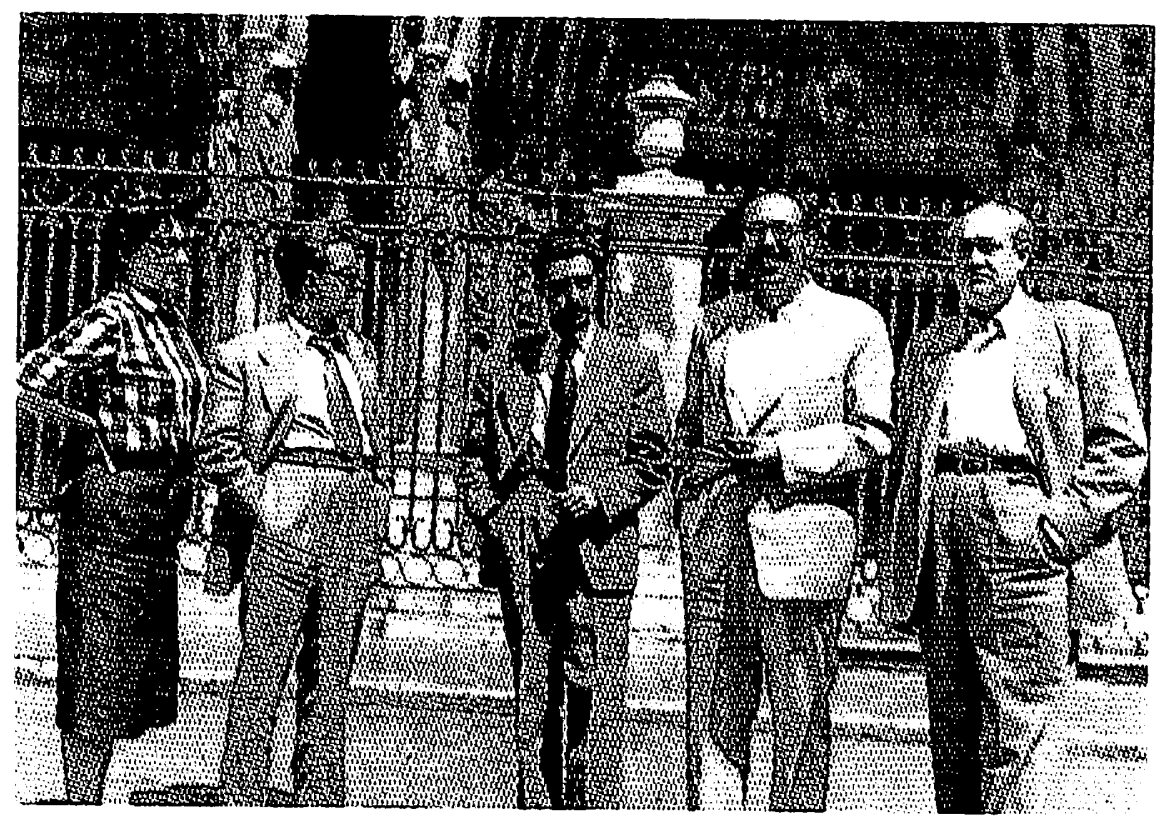

Trina Mercader, Miguel Fernández, desconocido, Rafoel Morales y Gabriel Celaya, Santiago de Compostela, 1954. 


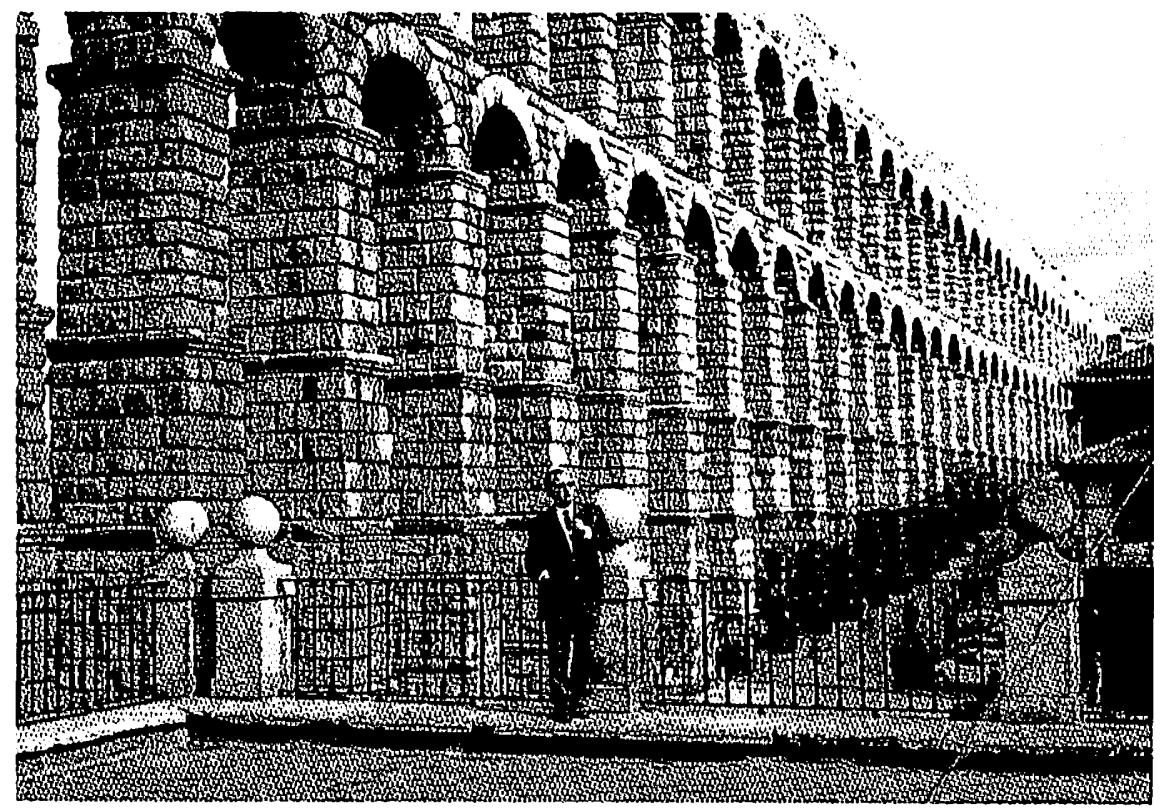

Miguel Femández ante el Acueducto de Segovio. 
Pedro de Lorenzo, Camilo José Cela, Miguel Fernández y Francisco Mir Bertanga en la Puerta de Santiago de Melilla la Vieja.

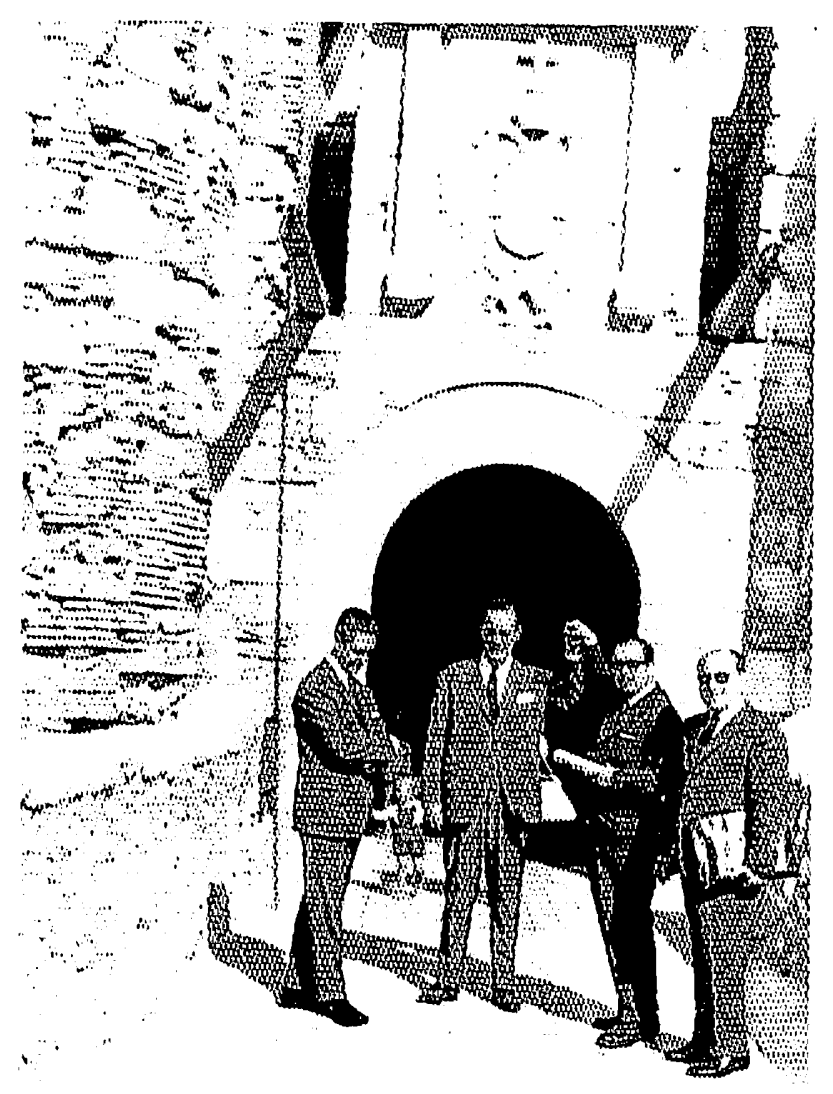


De izquierda a derecha: (primera fila) Carlos Rodriguez Iglesias, señora Alberracin, Juan Llamas, Gerardo Diego, Francisco Mir Berlanga, señor Gutiérrez, Juen Martinez Ruizi (segunda fila) Eledio Sos, Pio Gómez Niza, Miguel Fernández, Jacinto López Gorgé, Frencisco Salgueiro, Manuel López Ochoa. Melillo, 1963.

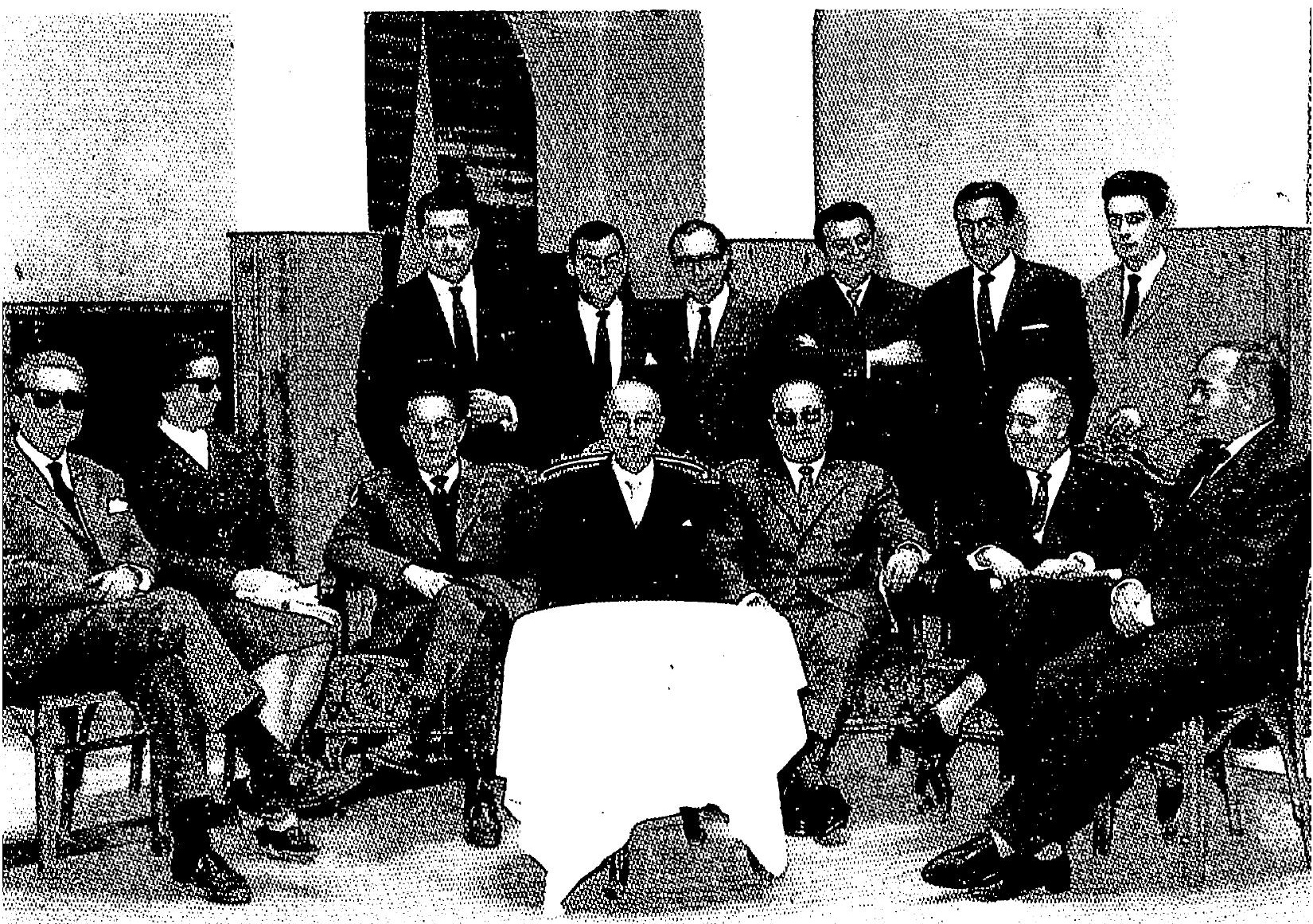


SONETO XXIV

DE naufracio coral, soñaludo y roto, en playas del amor, mar que te humilla, tu baño esponjas cuando el cuerpoovil la desnudo al friro en tu flotar remoto.

No linfos vistes pues nadaudo azoto iras de quien no dlcanza ta albd orilla y alli sestea en la mejada quillo la espalda en yodos, cruel del maremoto.

si el rapto fue por obra de delfines, toros de Europa con su cuerna embisten asolando la a rena de los peces.

Huyes por deseante a otos confinel; rieudo corres y con alfas visten salados senos, pezonadas weces.

Cecruel Terñande?

(De "Eros y Anteros". 1976)

ROSTRO DE CADA DIA

PARE yo la berlind por extasiarme quedo en ese violeta que se filtra en las flores en la hora decive del sol de los galanes. Alli la vista larga sus iris los reered tal sonar de la luz, cuando esplende armaniosa. Quise lo que tal vide, aprisionar en aures para luego el reflejo de ese color raftarlo $y$ ponérters a ti, madonna que no sabes cono wi coche pára sus bridas en ta acequia por ver si tu halda roja inclíname de hingos.

$$
\text { Misuel Ternändi?. }
$$

(De Discurso sobre el päremo". 1982)

70 
Miguel Fernández y su esposa Lolita Bartolomé en la biblicteco

de su casa en 1966. A la derecha el cuadro El muchacho de chaleco rojo.

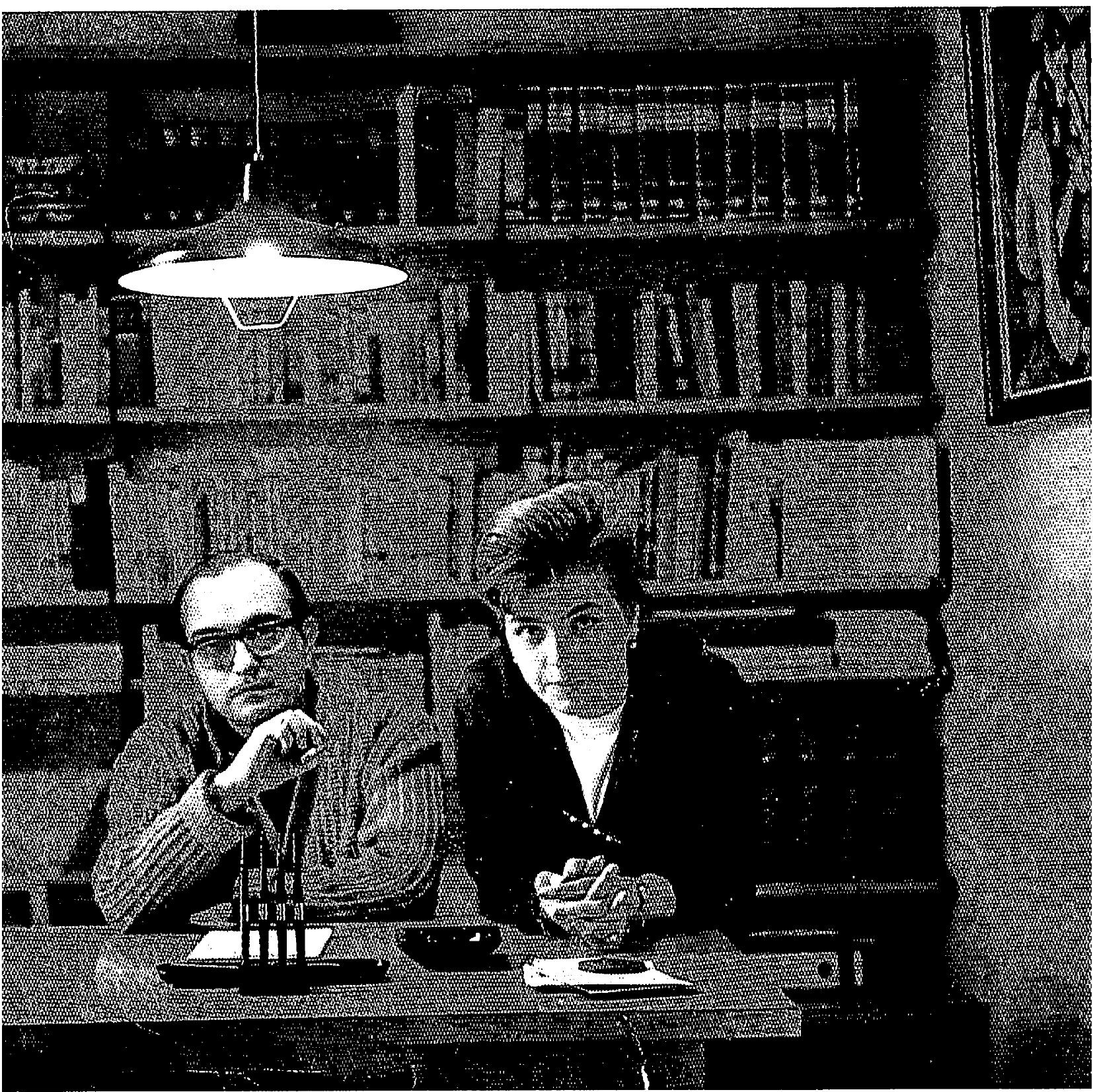


SONETO MUTANTE

OH Meritón de llonsi yonsel aita acuibero gentil rinsu paladio triscí a farores donde boven ario Ariosto fuese por aboenta helada. Dime, dimú, una Arsolida pentada ah que vesania decima estuario si anexado Alejaudro y ambo sorio y sirvo llambi alforta pasa el haida. ¿Tuten le plis, y a jórbido el joirbido, aguamantosa per le plinto vera ixdeuico el doncel a Guatemala?

Dixit que colibri vase al oncido dixit el fabiáu la bieu madura esféra.

iQue difa a morto quien a guati empala!

$$
\begin{aligned}
& \text { Huped Frnāede } \\
& \text { (29.5.1981) }
\end{aligned}
$$

Queri do trie lwis: I lup po dicen que on hermético. Ulipes

72 
Retrato de Miguel Fernández realizado por F. Hernández.

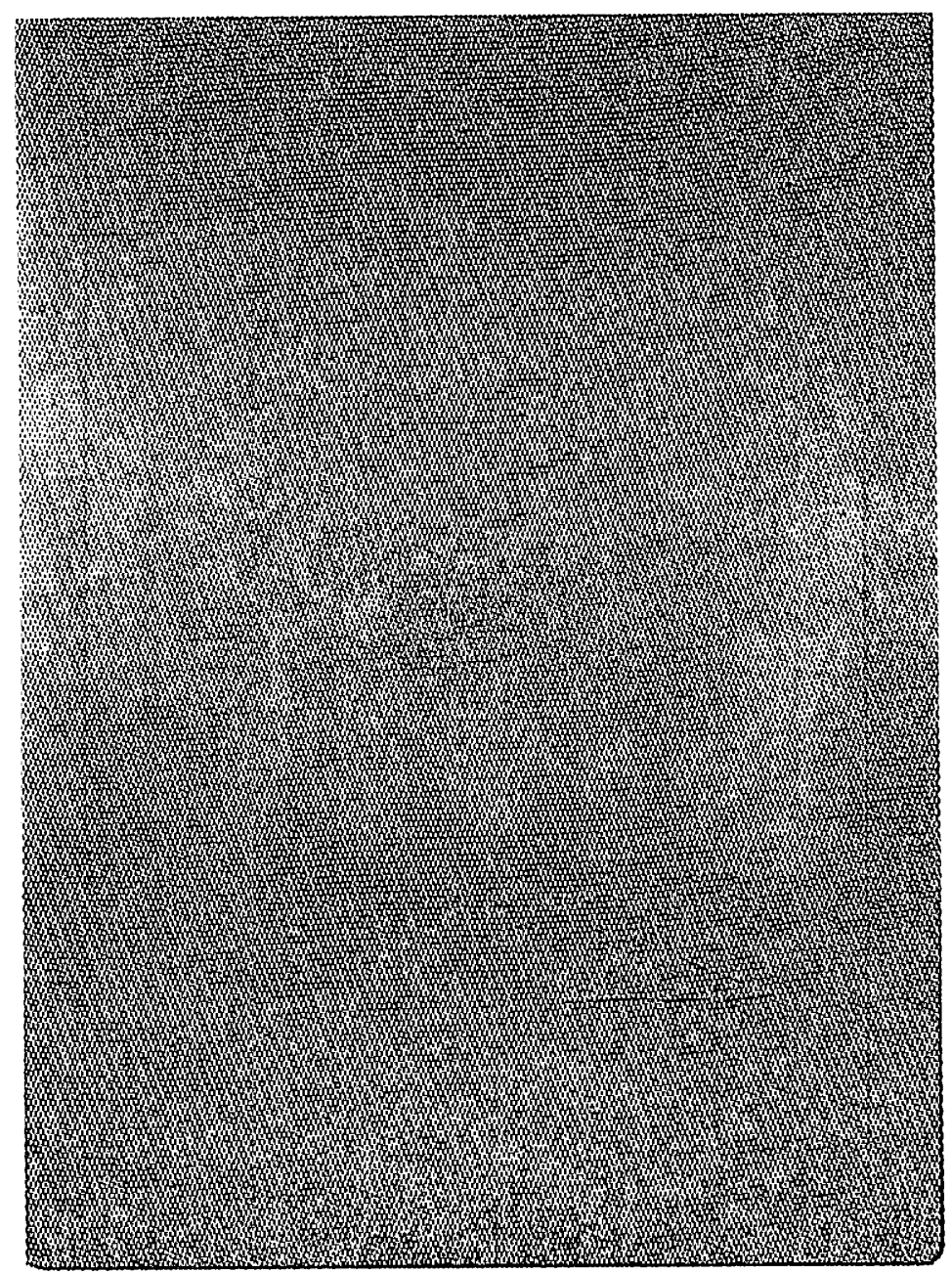




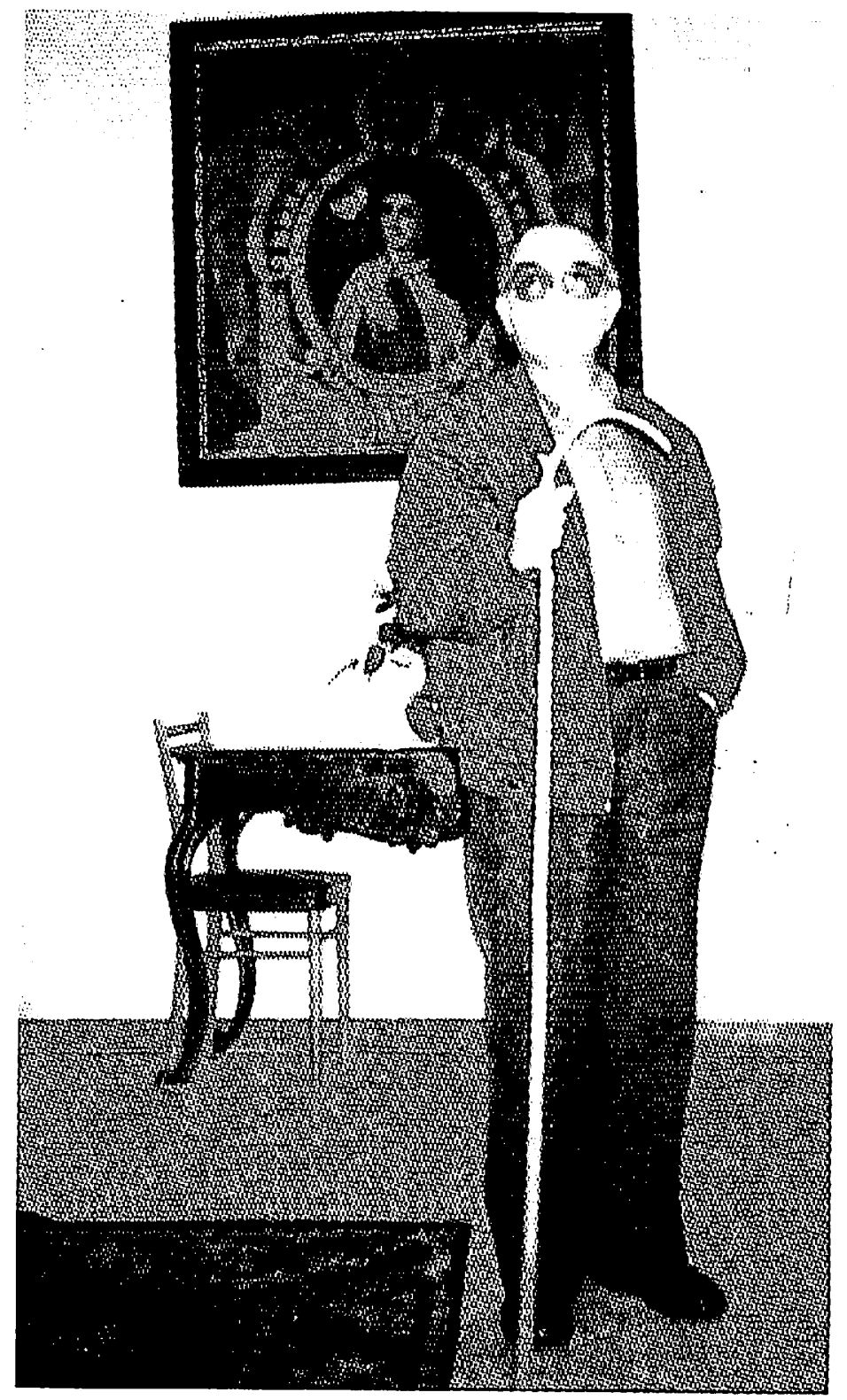

Miguel Fernóndez en el convento de los Carmelitas de Granada con el báculo de sen Juan de la Cruz. 


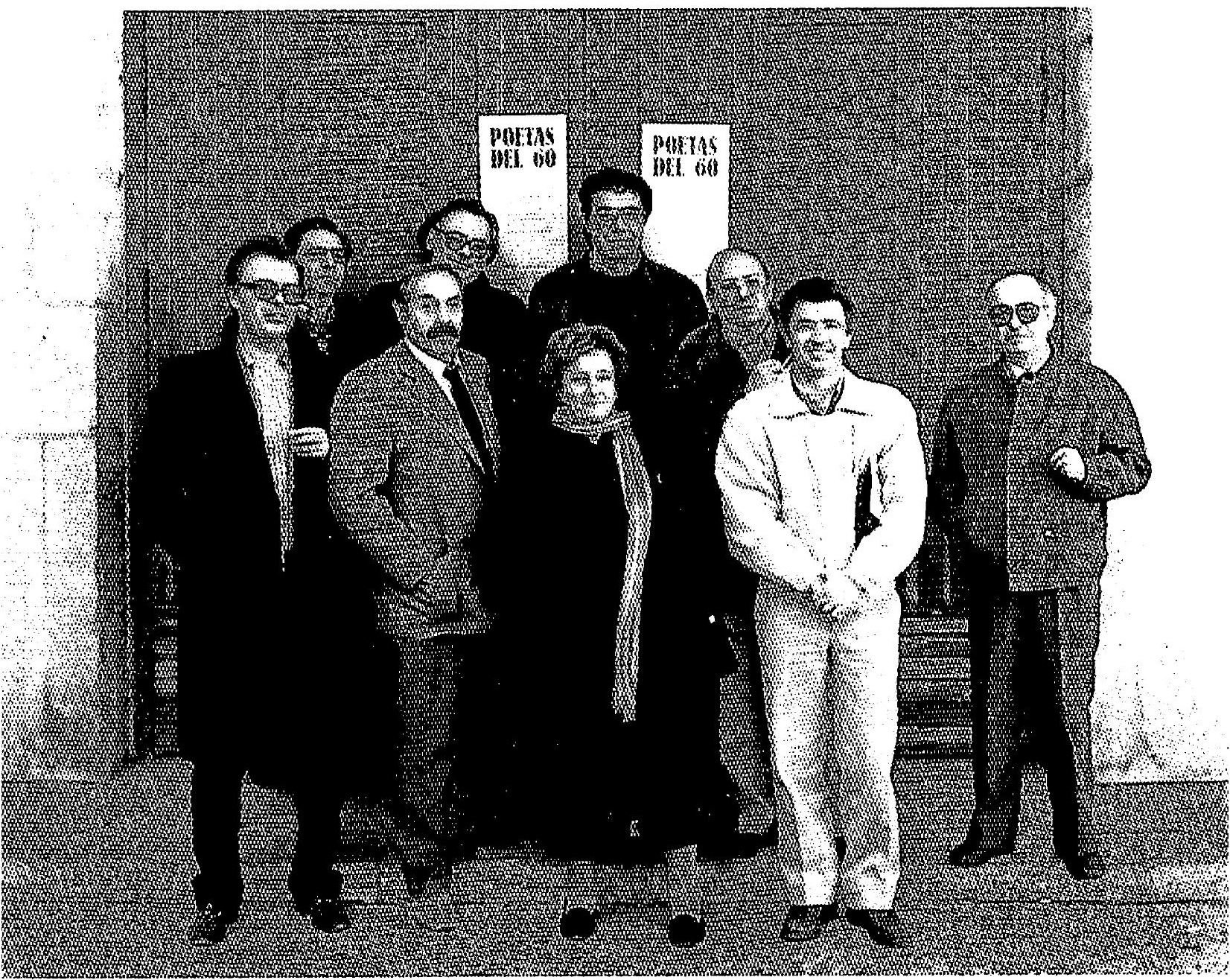

Poetas del 60 en Zamora. De izquierda a derecha: (primera fila) Antonio Hernández, Jesús Hilario Tundidor, Pilar Palomo (responsable del área de cultura del Ayuntamiento de Zamora), Miguel Fernández; (segunda fila) Manuel Rios Ruiz, Joaquin Benito de Lucas, Angel Garcia López, Diego Jesús Jiménez. 


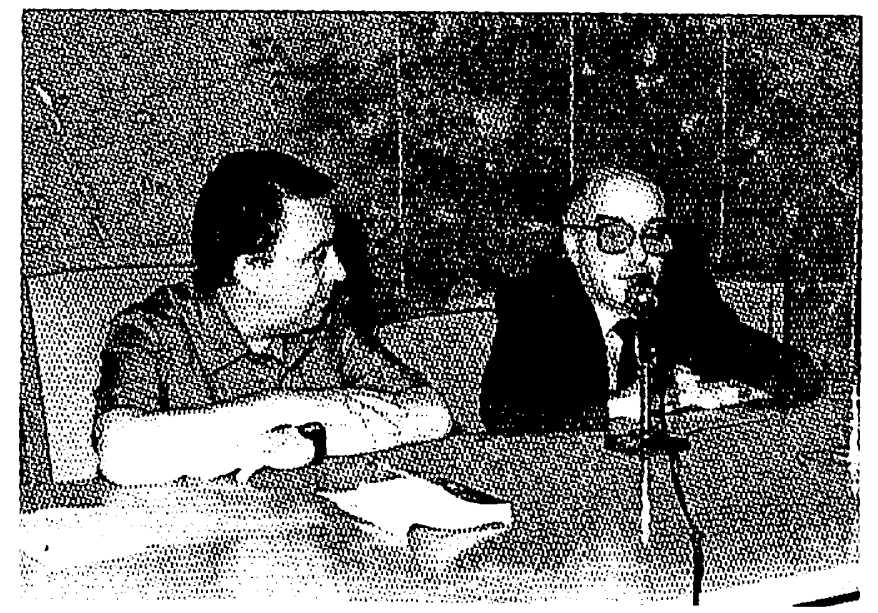

Miguel Femández y Claudio Rodriguez en Melilla, octubre de 1985.

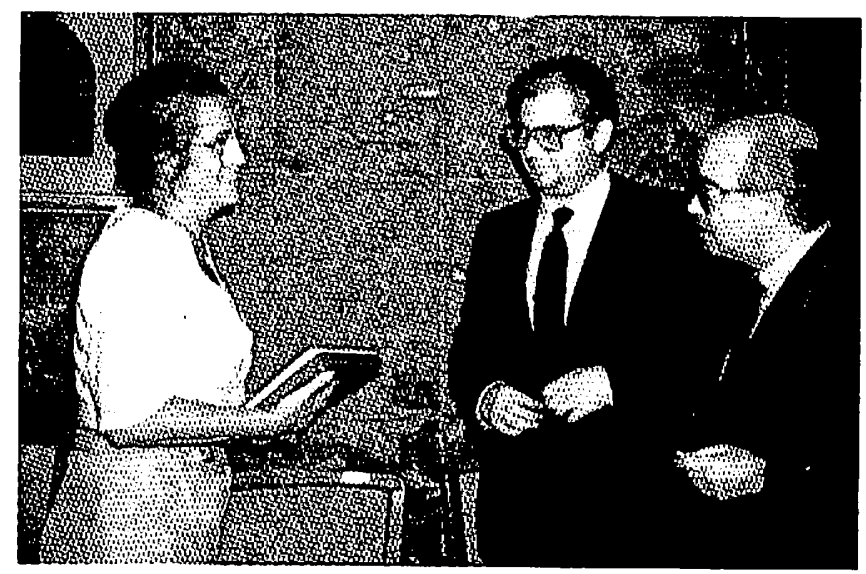

Maria Victoria Afencia, José Luis Fernández de la Torre y Miguel Fernández. 


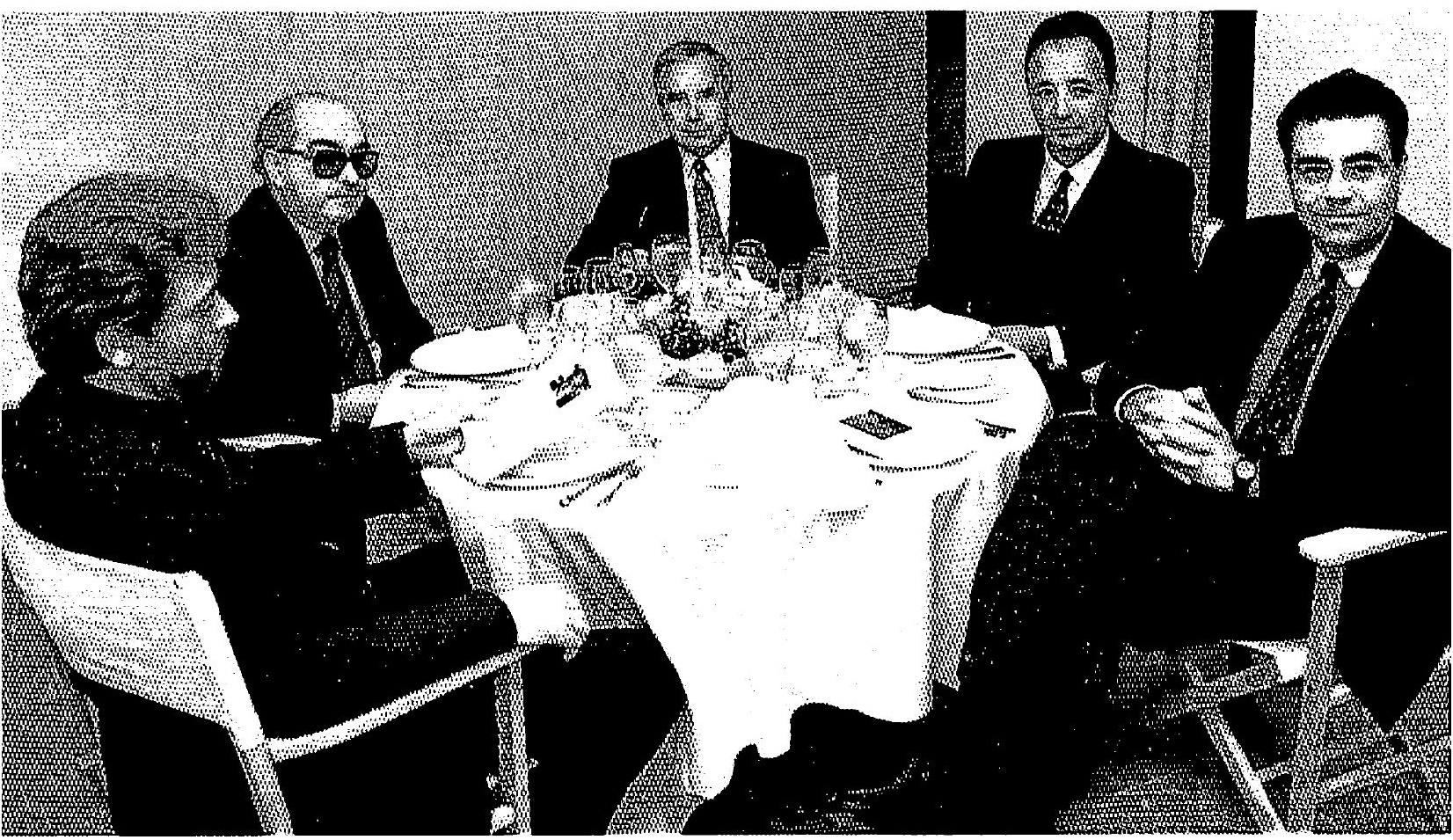

Jurado del Premio Internacional de Poesía "Ciudad de Melilla", 1991. De izquierda a derecha: Juan Carlos Suñén, Miguel Fernández, Pablo Garcia Baena, Arcadio López Casanovas, Jaime Siles. 
El poema "QASIDA DEL FIEL AMDR DE BEN AL-LABBANA DE DENIA fue escrito A MUTAMID DE SEVILLA". fue escrito el diecisiete de marzo de do por su dutor ochenta y seis y lé de verano de la eh la universidad el mes de agnsto cultad de Axilah en mende que didua del mismo año, en un hoal key topeta Universidad' tributó Queda coeta de sevilla.

profesor coy a del mismo en poler del versity college dick Gallagher, de la Uwta al autor de Dublih, guien soliciporarlo a un texto inédito pird incarparecion und autolo gia bilingüe en premo. I gualmente, para un homenaje a Manvel Alvar, ze pide colbboraciōn al poeto y

Aquí se escribe el mismo en papel marca "Villa seca", de primera clase, cuadernillo que le regalara Don losé María de Possío eu su despacho del Ateneo de Machi', al. Y la pluma empleada es marea "Dupont", te aro de verutidies quilates.

El presente documento queta en propiedad inoiviso de Dá Matia del Carmen Hoybs, y de D. Jose Luis Fernáudez de la Torre.

$$
\text { LAVS DEO }
$$

(En Mellla, a dps de Enero del año de gracia de ricl noveciantos ochenta y siote)

$$
\text { Cexfuel Fryau dez. }
$$




\section{QASIDA DEL FIEL AMOR DE BEN ALLLABBANA DE DENIA,}

A MUTAMID DE SEVILLA

AHORA en Agmat, mirey, enando el potente Atlas avasalla con sus duras barrancas que ensombrecen tus predios, esta choza de cāñamo y estos hulecos adobes que Son yo tu palacio, doude la lluvia mansa da luz a la paimers y y tu corone es nidal que sostuviere tanta y nunce niña hubo lavaubera cercana a los que putiera troecrte la malld plato recuerdo mieutras tiemblan mis dedos musitanio suras en el rosario aquella tardes sepian de los guaial guivires yucente en tre opllekeia, entre las lmo havias cercano al surtidor de dasulejos vidriados con ion tus borceguía de color de camela, de un cordoban purisimo recitaudo diwanes de Ben' Zaydun. O encendieudo la ontorcho de madera de olvo, pare alumbrar las dguas del Río presuroso eu doute los remeros a sa vez incendiaban resikas de Aljarafe,

miectras crotals ébrios y baudy as lucion sus piñoves de azucares. 

I tú, señor, dichoso en la belleza por zer como àmbar de alberces para que las cerámicas sezh rubi de die demas y aquellos taleomaues cumpliesen el destino, mas no el de tus principes, tan niños, que concerán el reto de tu. cuerpo ey/aulado. Ahord en Agmat, mi rey, queba wi huella y me vueloo de eppalias a ia gran corlitiera Por no verte rehen ol hueso enecabenods Si a tu cedend cantas, tam mierfono y reuada Pues venceior por siempre serás ectre mis lagrimas

Uipeel Fernănder

80 